\title{
Reflections, recommendations, and minor utopian visions for a game we love
}

In 2008, the magazine Golf Digest published a special feature on 'golf and environmental issues' that included an interview with Brent Blackwelder, a Duke University golf team alumnus who went on to become president of the American branch of the environmental non-governmental organization Friends of the Earth. To conclude the interview, Blackwelder was asked, "What would golf be like in a perfect world?" He responded as follows:

You'd be playing on an organic course. The maintenance equipment would be charged by solar power. Recycled water would be used for irrigation, and used efficiently and sparingly. There'd be a great variety of wildlife habitats. This idea that you've got to make everything look like a miniature golf course with a green carpet is crazy. It's the same problem that we see with these lawn fetishes - all the water and chemicals and energy that are used for a lawn that just sits there. So let's get back to the rugged qualities of the game. People ought to read the history of golf. (Quoted in Barton, 2008)

We have referred to this Golf Digest special issue at other points in this book, given that it includes candid interviews with key figures in and around the golf industry such as course superintendent Jeff Carlson, course architect Mike Hurdzan, and pesticide activist Jay Feldman. At this point in our analysis, we see Blackwelder's idea of what golf 'could be' as particularly provocative and valuable. Most of all, Blackwelder's vision of golf's (organic) future can be seen as a step towards unsettling established wisdom on golf's relationship with the environment in a 'radical but non-partisan' and 'utopian but realistic' way. It is radical because it suggests a transformational response to golf-related environmental problems: to carry out Blackwelder's vision would mean to undermine existing relationships between the chemical industry and golf industry, thus upending a major profit-oriented and corporate-driven relationship. This is not insignificant if we remember the relationships currently in place between the chemical industry, the golf industry, and governments, as outlined in Chapters 5, 6, and 7. At the same time, while Blackwelder is critical of the culture and incentive 
systems that underlie the ongoing drive for pristine golf courses, we also see Blackwelder's vision as non-partisan in the sense that he is also embracing the pro-environment innovations that emerge from the development of new technologies (e.g. solar powered maintenance equipment). In one short passage, then, Blackwelder offers an assessment of golf that is in line with a critical 'treadmill of production' perspective and reflects the faith in technological innovation favoured by advocates of 'responsible golf' and ecological modernization. This is a vision of environmentally friendly golf that appears to be relatively unclouded by a commitment to any particular ideological stance. It brings together perspectives on our environmental future generally considered to be incompatible. ${ }^{1}$

We also think Blackwelder's response is thoughtful in the sense that it sensitive to the contexts within which the golf industry currently exists and the contexts from which it evolved. In fact, Blackwelder's vision reminds us in some ways of C. Wright Mills classic book The Sociological Imagination - a book that included Mills' argument that rigorous sociological analysis requires 'historical and comparative sensitivity'. What Mills (1959) was suggesting was that being sensitive to different social and historical contexts makes it easier for sociologists to see and show why the institutional arrangements that we take for granted - arrangements that seem unchangeable, even 'natural' - are much easier to modify, even transform, than might seem apparent on the surface. In this case, Blackwelder 'imagined' a time in history when chemical-aided golf was not the status quo. This would seem to imply that there is nothing 'natural' about golf's present-day status quo and that, as such, what we have called responsible golf need not remain hegemonic going forward. Furthermore, and by implicitly comparing chemical-intensive golf to organic golf, Blackwelder is drawing attention to the fact that another kind of golf - a more environmentally friendly version of golf - is not only possible, but it exists (albeit not in the exact form Blackwelder describes).

Ultimately, we would argue that Blackwelder's vision is reminiscent of what historian Jay Winter (2006) calls a 'minor Utopia'. For Winter, to seek a minor Utopia does not mean to attempt to create a 'perfect' situation - since attempts to seek perfection (what he calls a 'major Utopia') are unrealistic and can be quite dangerous (remembering here, for example, the utopian projects of Nazi Germany). Instead, Winter describes minor Utopias as "partial transformations" and "steps on the way to less violent and less unjust societies" (Winter, 2006: 208).

In a similar way, sociologist Erik Olin Wright $(2007,2010)$ has argued that it is important to visualize what the world 'could be like' and to identify instances 
where versions of what he calls 'Real Utopias" already exist. The idea here is that 'social dreaming' of this sort is a crucial step towards the attainment of the radical social and environmental changes needed at the contemporary moment (see Claeys and Tower Sargent, 1999). Wright further suggests that effectively visualizing, and ultimately realizing, some version of a Real Utopia requires an initial assessment and critique of existing institutional arrangements. Only then, with a better understanding of existing problems, does it make sense to try social and environmental experiments that are intended to create a more equitable and sustainable world. As he states:

To be a radical critic of existing institutions and social structures is to identify harms that are generated by existing arrangements, to formulate alternatives which mitigate those harms, and to propose transformative strategies for realizing those alternatives. (Wright, 2007: 26)

Wright uses the metaphor of a pond to help us think about how a dominant 'ecosystem' (e.g. responsible golf) might begin to change when the pond is exposed to 'alien species' (e.g. chemical-free golf). He argues that thinking of society as an ecosystem where "everything is interdependent, but interactions do not constitute a tightly functionalized totality" can also help us imagine alternatives and inspire hope for change (Wright, 2013: 9). His point is that an ecosystem can be transformed by introducing "an alien species that initially finds a niche and then gradually displaces certain other species" (Wright, 2013: 9). While Wright recognizes that there are never guarantees about the positive results of such experiments - new/alien species often die or are eliminated - the idea is that attempts to offer alternatives and inspire thinking about what is possible are crucial if we have any hope of triggering radical social and cultural changes.

Inspired by Blackwelder's vision for golf going forward and by academic conceptions of 'utopian' possibilities, we spend this final chapter reviewing golf's environmental past and present - and thinking with some imagination about its future. Initially, we offer an overview of what we see as the main findings that emerged from our research, as presented over the course of this book. Following this, we present a set of recommendations that are intended to inspire concrete thinking about how to promote healthier and more ethical relationships between the golf industry and its numerous stakeholders - paying particular attention, of course, to environmental issues. As you would expect from reading to this point, the list of stakeholders we are concerned with in making these recommendations is quite lengthy. It includes the multitude of people who golf or who live 
near or work on golf courses, people generally concerned with the health- and environment-related impacts of practices such as pesticide spraying; and - not to be forgotten - the voiceless flora and fauna impacted by golf's occupation of land. In this chapter, we intend therefore to offer suggestions for translating the problems and opportunities we identified through our research into concrete actions, and thus into social and cultural changes - and then, even further, into 'minor' or 'real' golf Utopias. With Wright's vision of the pond in mind, our goal is to consider how the dominant ecosystems in and around golf might be altered through interventions that are both smaller and larger in scope. Finally, we conclude this chapter by acknowledging the many relevant topics and issues we were unable or chose not to pursue in this book. At this time we also outline an agenda for future research on golf, the environment, and globalization.

\section{The greening of golf: a summary of key findings}

Below we outline the main findings that emerged during our research. These findings shed light on the 'greening of golf' across the twentieth and early twenty-first century and, by our assessment, lingering concerns and nascent possibilities pertaining to the golf industry's relationship with the environment.

\section{Finding 1: Members of the golf industry have embraced environmentalism, especially since the late 1970s}

It is perhaps easy to overlook this finding, given that the past two chapters centred on radical responses to golf-related environmental questions (organic golf and anti-golf protests) and given that we ourselves highlighted lingering issues with responsible golf. Yet our analysis in Chapters 5, 6 and 7 indeed identified important changes in the golf industry, as well as an overall shift from a pro-golf (i.e. Promethean) position marked by denialism on environmental matters to a 'responsible', ecological modernist position that situates the environment as a crucial matter of concern. IPM, for example, while still a source of consternation for some, marks a point of departure from an earlier time when golf courses were allegedly 'plastered' with synthetic chemicals - the spectre of Augusta National syndrome a driving force. The education and certification programmes adopted by organizations such as the GCSAA are, in principle, steps towards improved environmental outcomes. 


\section{Finding 2: There are limits to the 'green' sensibilities of those representing the mainstream golf industry}

A common refrain for activists and environmental groups is that minimizing pesticide exposure (as per IPM) is still not precautionary enough. Our introductory chapter highlighted research suggesting that synthetic chemicals still pose risks, even if these risks are not quite as clear or as pressing as they were in the case of products such as DDT.

What a historical analysis - the likes of which we have undertaken - reveals is how the golf industry has come to defend synthetic chemicals almost as a default position over time (recognizing the occasional presence of counter-hegemonic views as well). As we said in Chapter 5, the golf industry has seemingly known the answer - pesticides are needed - before the question is even asked. The close relationship between the chemical and golf industries is not irrelevant in this regard, with the former helping the latter by, for example, lending financial support to the Environmental Institute for Golf.

The 'limits' on the greening of golf also pertain to the economic growth agenda that, understandably, is cherished by industry representatives. The desire to build new golf courses at a rapid pace is one that dates back at least a century. What it means in a time of responsible golf, however, is that the efficiencies won through precision irrigation, among other tactics, are potentially offset by golf's expansionary imperative (which includes a desire for global expansion). Does it truly matter that golf courses can be watered with greater efficiency when new courses can, at the same time, be built on Sites of Special Scientific Interest, as in Menie, Scotland?

\section{Finding 3: In a time of responsible golf, appearing 'green' is just as important as being 'green'}

Chapter 6 showed that professionalization in the golf industry in North America has meant enhancing educational programmes and devising formal mechanisms for liaising with the public and with governments. Of course, it is perfectly acceptable for an industry to develop in this way. The concern that arises, however, is when internal and external messaging are at odds. We cited the rather candid reflections of former GCSAA President Timothy O'Neill in making this point: "Existing environmental data is limited and not complete, uniform or centralized. Information provided to the media, government and industry often is inaccurate or misleading. This is not a healthy state of affairs" (O’Neill, 2006: 13, emphasis added). 


\section{Finding 4: Governments have responded in \\ kind to the golf industry's leadership on environmental matters}

This is the realization of post-politics: whereas industry has become more responsible in managing the environment and developing mechanisms for communicating their ethos of responsibility, governments (in Canada especially) have been keen to accept industry leadership in a wider context where volunteerism has emerged as a key environmental policy instrument. The 'consensus' that this is the best way forward rests on the alleged balancing of economic and environmental priorities - though from a critical perspective (one evinced, for example, by a government committee formed to review pesticide legislation in Canada in the year 2000), regulatory systems of this kind tilt the balance between economic and environmental sustainability to the side of the former. In other words, and as Hannigan (2006) says in describing the notion of 'environmental managerialism', governments are apt to create policies and oversight systems that gesture towards environmental protection while in fact privileging industry's economic well-being. The outcome in the case of Ontario's ostensibly stringent Cosmetic Pesticides Ban Act is a situation whereby those contesting cosmetic pesticide legislation in the courtroom in the past are now themselves involved in systems of environmental oversight.

\section{Finding 5: Local and global 'anti-golf' movements have emerged over time, with varying goals and varying levels of success}

Said otherwise, the 'light-green' post-political consensus described in Chapters 5-7 of this book has not been readily accepted by all. The most radical response to golf's post-war development - including its global expansion - is GAGM, which questions the merits of tactics such as IPM and calls for golf courses to be abolished. More local 'anti-golf' responses question golf course development projects within particular contexts. In Chapter 8, we featured the Tripping up Trump movement as a case in point - one that was successful in some modest ways, though ultimately failed in the task of blocking Donald Trump's course construction project on an environmental SSSI. 


\section{Finding 6: 'Organic golf' has gained some traction and publicity as an alternative to responsible golf, though there are barriers that currently prevent organic golf from becoming a more mainstream option}

These barriers include: the overall cost of maintaining an organic golf course that can compete (on an aesthetic level especially, and to a certain extent playability level) with non-organic courses; a lack of organization among organic golf advocates; a lack of support from the broader golf industry; and a reluctance on the part of many governments to mandate chemical-free golf. Difficulties faced by organic golf advocates are also no doubt a reflection of the difficulties faced by the golf industry more generally - an industry that has struggled in the recent recession years to remain profitable in particular areas (although the industry continues to expand in other areas). It is also well known that maintaining an organic golf course comes with unique challenges dependent on the geographic context in which the course is situated, with moderate climates being preferable.

Nonetheless, if we revisit our PAAR continuum (see Figure 1 from Chapter 2), organic golf presents us with an 'alter-golf' response that is different from that preferred by the mainstream golf industry. Organic golf is transformative in that it effectively seeks to disentangle the golf and chemical industries. In Chapter 9, we suggested that organic golf to some extent returns the sport of golf to its roots - for example, in privileging 'pre-modern' tactics such as hand weeding. Organic golf might also undermine Augusta National syndrome - the 'illness' whereby consumers come to expect playing conditions on par with those at Augusta National Golf Club, home of the Master's tournament - in the sense that on-course 'blemishes' are not deemed grounds for synthetic chemical applications. That said, it is noteworthy in this regard that one representative from an organic golf course told us that he hoped consumers would fail to distinguish between his course and a non-organic alternative.

\section{Seeking 'minor Utopias': recommendations for a greener and more ethical golf culture}

These six findings form the central narrative of The greening of golf. With these findings in mind, we now offer a set of recommendations for changing current environment-related practices as they pertain to golf - recommendations that are driven by our ultimate concern with environmental and public health. These 
recommendations are responses to the problems and opportunities for change that emerged from our research.

\section{Recommendation 1: Move towards a 'phased in' ban on the use of cosmetic non-organic chemicals on all golf courses}

Although there are various ways of inspiring behavioural and cultural change, we think that elected officials who have been mandated to work in the best interest of those they represent - which means attending to environmental and public health concerns - should be compelled to ban non-essential pesticide use across the board, as this is the most straightforward strategy for creating change. Such bans of chemical usage, guided by and justified through a precautionary approach to environmental and public health, are becoming commonplace, as we noted in Chapter 7. In the same chapter we also argued that the reasons for exempting golf courses from such bans are, in our view, uncompelling and problematic; hence our recommendation.

This recommendation is obviously aimed at governments (e.g. provincial governments in Canada) that centre their chemical-use policies on reducing cosmetic chemical applications on golf courses, but not eliminating them. Our suggestion is inspired by lawmakers in Denmark who recently developed binding regulations aimed at phasing out chemical usage on golf courses over time (Beyond Pesticides, 2011; also see R\&A, 2013). This approach ostensibly recognizes the difficult challenge the golf industry faces in changing now well-established course maintenance practices, while also offering a clear statement that radical change in the name of environmental and public health is the most precautionary way forward.

In making this suggestion, we are advocating for what we call 'rear-view mirror' policy making as a way of guiding public policy away from mistakes of the past. As noted throughout this book, when governments take an 'environmental managerialist' approach, they create policies and structures that are favourable to industry, and, in theory, to economic growth. To use a car metaphor, they see mainly through the windshield to what lies ahead economically, and rely heavily on industry-produced knowledge (e.g. on the risks associated with chemicals) as the engine to propel them forward. Indeed, debates over pesticides tend to centre on scientific claims regarding their safety (or, at least, their 'riskiness'), with chemical advocates and critics advancing evidence in support of their respective causes. 
We do not suggest that chemical research is irrelevant by any means, but we do contend that historical insights should be more heavily weighted in deciding future policy directions. When it comes to golf and the environment, there are three germane points that this 'rear-view mirror' approach unveils. First, and as one of our respondents from an organic course pointed out, the use of turfgrass chemicals is a relatively new phenomenon - for centuries golf courses fared quite well without their use. A turn to chemical-free golf, then, is in fact then a return to an older style of course management. Second, the time period from the late 1960 s to the present is marked by growing public scrutiny over the necessity of chemicals, and, indeed, by the reduced usage of chemicals on many noteworthy golf courses. The logical conclusion of these trends is to ultimately excise chemicals completely, even if this takes some time to achieve. The long arc of golf's pesticide usage - from a time of helicopter-aided DDT spraying in the 1960s to IPM's de jure guidelines for restrained pesticide usage in the present moment - points in the direction of outright elimination of synthetic chemicals from golf courses anyway. Third, and most important, a historical view reveals that the science surrounding turfgrass products is always in flux, for the chemicals deemed 'unrisky' at one point (e.g. DDT in the 1960s and 1970s) are sometimes later revealed to be more toxic than once thought. This means that even the precautionary principle favoured by environmentalists might not be stringent enough, since proving the absolute safety of chemicals (required under this principle) is perhaps impossible. Based on our interviews with golf course superintendents, we recognize the stresses that would come from an immediate excising of turfgrass chemicals from golf course management; we thus suggest that the Danish model and its gradual phasing out of chemicals stands as a useful template for other governments. Indeed, even if the 'sunsetting' of pesticides has an 'end by' date far in the distance, it would expedite the process of finding innovative management solutions. In other words, an impending ban of this kind would direct the incredible resourcefulness, innovation, and empirical wherewithal of individuals such as golf superintendents towards fully precautionary measures, as opposed to achieving the seemingly impossible standard of Augusta National syndrome.

Of course, we remain attentive to the very real impediments to achieving policy changes. For example, and as the Standing Committee formed in the Canadian House of Commons in 2000 pointed out, those with decision-making power often have a vested interest in maintaining the status quo. Our decision to lead with this recommendation is a way of inspiring a revisiting of the arguments offered by the Standing Committee, since the suggestion made by this 
committee to dissolve conflicts of interest in environmental regulation is as relevant today as it was at the time it was made.

To be sure, we cannot know with complete certainty the impacts of this sort of policy change. What we do know, however, is that those who are compelled to use chemicals on golf courses for fear of losing customers (and perhaps for fear of losing their jobs) are unlikely to engage in voluntary non-chemical experiments any time soon, even if the potential benefits of a successful transition to an organic course are recognized. The economic stakes, it would seem, are too high unless the playing field is levelled (at least when it comes to chemical versus non-chemical courses) through an across-the-board ban.

With Wright's metaphor of 'the pond' in mind, we suggest that introducing a non-chemical mandate to golf's ecosystem would be most likely to result in an adaptation that would, over time, be scarcely noticeable. Ironically, and given the results of other scenarios that might play out without such a mandate, there is little risk for government here - noting that the chemical industry will undoubtedly adapt to this new scenario, as they are already doing through the production of organic inputs.

\section{Recommendation 2: To support recommendation 1, begin an education campaign and website called 'Seeing Golfscapes Differently' that features outstanding chemical-free golf courses around the world that do not conform to the 'pristine and predictable' image associated with Augusta National}

We think the Seeing Golfscapes Differently project would be an excellent venue for the promotion of organic golf courses especially - and could perhaps be considered a strategy for inspiring more superintendents and owners who are 'close to organic' to make a full transition to this end point. ${ }^{2}$ The idea here would be to demonstrate what is possible when it comes to offering alternative forms of aesthetically pleasing chemical-free golf and to inspire local golfers to seek out these alternatives. The goal is not to promote global tourism, which comes with its own travel-related environmental issues - although we recognize that this could be an unintended consequence of this initiative. We appreciate the paradoxes embedded in this last point, since while we would hope that these courses would be economically viable by catering to local golfers (thereby reducing their environmental footprint), we recognize that global golf tourism aids with the issue of economic viability. 


\section{Recommendation 3: Until a chemical ban is fully instituted, require every golf course to prominently post on its website and scorecard a list of 'ingredients' that are used on the course}

This would feature a list of chemical inputs, with direct links from this list to the website of a non-partisan health organization that describes each chemical and its potential risks (e.g. the World Health Organization, or government-based websites reviewed by impartial experts on chemical risk assessments). The ingredients would also list the amount of water used on the course and the source from which water is derived. This information would also be linked to a non-partisan website that offers information about best practices in terms of water usage, and a list of risks and concerns. Indeed, the Cosmetic Pesticides Ban Act in Ontario already requires golf courses to list their chemical usage online, though we doubt that many golfers in fact access this information.

\section{Recommendation 4: Place higher priority on community voices in the decision to build golf courses in the first place}

Even if golf were to become fully organic, there would still be environmental issues for industry members to contemplate. In theory, Donald Trump might have pledged that his course in Menie, Scotland would be chemical free ahead of its development. Even so, it is unlikely that this would have satisfied community residents concerned for the sand dunes along Scotland's shoreline, deemed a SSSI.

There are surely many cases where golf courses are built only after community dialogue. Indeed, this recommendation stems from the making of the Vineyard organic golf course whose chemical-free ethos was built on the back of community demands (see Chapter 9). In making this recommendation, we also have in mind Harvey Neo's (2010) research on golf in Singapore, and specifically his finding that the integration of multiple stakeholders in dialogue on golf course development is not always as effective as it seems on the surface. The taken-for-granted starting point (or post-political consensus) that a golf course will in fact be built can undermine more radical perspectives. Still, there is a need to address environmental issues beyond chemical usage on golf courses, such as the occupation of green space that comes with an expansionary industry 
agenda. Giving agency to communities is a potential solution in this regard, and speaks to our vision of 'contextual golf' outlined below.

\section{Championing the local and the political: seeking contextual golf in a globalizing world}

All told, we view these recommendations as modest in nature: environmental issues are incredibly complex - made more so in contexts where economic growth is the highest of priorities - and so we see small steps and 'minor Utopias' as the only way forward. The spirit underlying these suggestions is that the range of actors involved in addressing golf-related environmental issues can and should be made as diverse as possible, and that the range of possible outcomes can and should be diversified as well. Both caveats are important. The rejoinder to this 'spirit' might be that multiple actors are already involved in environmental decision-making as it pertains to golf. For example, both environmental groups and the EPA participated in the making of the 'Environmental Principles for Golf Courses in the United States' in the mid-1990s (see Chapter 7). Still, as articulated above and throughout this book, we see limits on the extent to which 'green' initiatives can be adopted: this is a time where 'light-green' responses reign in the end. The golf industry's innovativeness in constructing and managing golf courses is most welcome, but we do not see the golf industry itself as best positioned to 'lead' the transformational changes that are needed in achieving a precautionary, chemical-free version of golf. Indeed, and following Robbins (2007), even though individuals such as golf superintendents are on the surface 'acting freely' - for example, in choosing to apply chemicals - there are also pressures to 'submit fully' to the ethereal but ever-present and powerful demands of a network of industries (or 'integrated circus', as per Chapter 9). The problem here is that the 'freedom to choose' to not use chemicals is often not really a viable choice. This is part of the reason that we have expressed empathy across this book for golf superintendents who must grapple with Augusta National syndrome while also accounting for their own green sensibilities.

But many of those elected to government positions are not subjects in this system in the same way as golf superintendents or others working in the golf industry. And although we recognize that governments have their own dual incentive system, whereby environmental and economic concerns must be dealt with simultaneously, we see 'environmental managerialism' as comparatively easier to overcome. At the very least, and in theory, governments are accountable 
to the public in ways that private businesses are not - thus targeting those who are ultimately mandated to deal with environmental concerns would seem to be the best use of resources.

Underlying these recommendations too is an acknowledgement that in some geographical locations and environmental conditions, discontinuing a golf course or choosing not to develop a new one should be considered the best option available. Playing golf is not a human right. It is a luxury and is only one way to be physically active, enjoy a leisure experience, and/or make a living. With this in mind, why would we take any chemical-related risks to maintain a golf course? Why should excessive water use on any course be acceptable?

What we are calling for, therefore, is contextual golf - the existence of golf courses only in circumstances where the sort of organic golf outlined by Blackwelder is environmentally and economically feasible - and a 'championing of the local'. We say this because we think the pressures associated with the modernization and globalization of golf - pressures to offer predictable leisure experiences for global tourists - are challenged when an ethics of environmental precaution is prioritized. This is also a 'championing of the political' (as opposed to the post-political) in the sense that questioning the viability of golf in particular contexts would lead to important and contentious debates. Our view is that reintroducing contentious debates about golf and environmental issues is important and necessary, and is reflective of a highly democratic and open (i.e. not foreclosed) political context. This is much different from a context where the most important decisions about how to deal with key sustainability-related issues are already made before consultation that effectively involves 'ironing out the details'. In fact, we think that openness to the notion that building or maintaining a golf course can be a bad idea also creates space for alternative recreational options that might be more inclusive and more socially and environmentally sustainable than golf is at present. Consider frisbee golf - an activity that is less reliant on space and does not require pristine settings. We find this alternative especially intriguing considering that frisbee golf courses have emerged on some former golf courses, including courses that have been left to grow over, and thus left for use by those not requiring a manicured space.

\section{Golf, globalization, and the future}

In the first chapter of this book, we indicated that our analysis herein was designed to make a contribution to the nascent research area known as critical 
golf studies - a body of literature that is just beginning to account for the range of golf-related issues noted above, among others. Our hope is that future research in this area will continue to explore topics examined in the preceding chapters while also assessing the linkages between these topics and other social issues. The latter include, for example: race-, ethnicity-, and gender-related inequalities that have been perpetuated through policies dictating who is allowed to play on particular golf courses; economic inequalities that have been reinforced through the private ownership of vast quantities of land for a sport that many cannot afford to play; and global inequalities that manifest through the exploitation of scarce water and land resources in countries of the Global South for sport and leisure tourism purposes.

These problems are centrally relevant to our study of environmental issues in the sense that the implicit rationale for preserving golf in the first place is that it is somehow a public good. We recognize here that there are ways in which golf is indeed a public good, noting the physical activity-related benefits for those who have access to and an interest in golf (e.g. see Parkkari et al., 2000) and the economic benefits that can be earned by those in the golf industry itself (e.g. course owners) and those featured in golf's wider 'integrated circus' (e.g. the apparel and equipment industry, the chemical industry, and the tourism industry). Still, if we weigh these benefits against the concerns that have been raised in this book about the potential health- and environment-related risks associated with golf, the 'golf is good for us' argument seems far less compelling. Moreover, if these benefits are only accessible to a small number of stakeholders, questions must be raised about the incredible space requirements for a game that remains exclusive in some ways.

\section{Globalization, golf, and the Olympics}

During our research we became especially cognizant of how our study of one of the major global issues of our time - environmental sustainability - has differing implications for those in different parts of the world. The movement of 'Americanized' versions of golf into less wealthy areas is reminiscent of concerns expressed by many scholars about the implications of sport-related global expansions more generally (Andrews et al., 2014). These issues were raised most explicitly in our discussion of social movements and sport, and especially the Global Anti-Golf Movement, in Chapter 8.

There is no better example of a global sport-related initiative that has for many years been the focal point of debates regarding social and environmental 
issues than the Olympic Games. In fact, the upcoming Rio 2016 Games has particular relevance here in the sense that it is being hosted in a city and country that is ostensibly a good 'fit' with the stated development-related goals of the International Olympic Committee (IOC). Rio is the city of the Global South that will, according to Olympic advocates, benefit from the apparent economic, social, and environmental gains that hosting a sport mega-event supposedly provides. In fact, and as Pentifallo and VanWynsberghe (2012) have argued, the choice of Rio for the Games reflects what many see as a trend towards the hosting of events in cities considered to be especially underdeveloped and 'in need' of help from Global North organizations such as the IOC. Of particular pertinence here is that the sport of golf has been (also controversially) reintroduced to the Olympic Games after being an official Olympic sport in 1900 and 1904. This reintroduction meant that a new golf course would be constructed for use during the Games.

The links between the critiques of the IOC and the range of global issues underlying golf, tourism, and environmental problems has not been lost on commentators focused on Rio 2016. Elena Hodges, writer for the activist news website Rio Olympics Neighborhood Watch (found at RioOnWatch.com) offered a compelling examination of this issue. The Olympic golf course, Hodges writes, is a microcosm for the problems with Rio 2016's infrastructure development:

The site chosen for the golf course sits on 1 million square meters of protected Atlantic Forest on the edge of the Marapendi lagoon in Barra da Tijuca. A mix of fragile mangroves, marshes, and sandbanks, the area contains about 300 identified species. A whole host of different animals will be threatened by new development in Marapendi, from herons to capybaras to endangered species such as the yellow-necked alligator, the beach lizard, and the crested guan. (Hodges, 2014)

Hodges goes on to problematize Complementary Law 125, which by her recounting was passed by Rio's city council to enable access to this land:

[T] he law passed in December 2012 is extreme in its provisions. First, it authorizes the construction of the golf course within the borders of the Marapendi Reserve, using the justification that building a golf course qualifies as sustainable use of the land. Additionally, it redraws the borders of the Marapendi Municipal Reserve in order to completely cut out the section that fell within the intended golf course site. The law effectively nullifies the area's "permanent protection" status, handing this piece of public land over to a private developer, RJZ Cyrela. (Hodges, 2014) 
Hodges also adds that the law in question gives the developer the right to build twenty-three new luxury on-site condominiums.

Implicit to this commentary on the whole is that those in Rio who are charged with organizing and hosting the Games must do major infrastructure upgrades to satisfy the requirements of the IOC - a global 'super NGO' that has no particular inherent interest in the range of local stakeholders that are impacted by the Games. In fact, it is well established that the intended and unintended consequences of preparing for and holding the Olympics can be understood as an impact of globalizing forces on local (host) cities (Hayes and Horne, 2011). Of course, the IOC has immense influence on local planning and governance decisions in cities around the world; the Games themselves also mobilize global capital and tourism (VanWynsberghe et al., 2013). That golf is implicated in the vortex of concerns associated with the Games is but another example of how golf is inseparable from broader concerns about global tourism and economic globalization - all issues examined in Chapter 8 especially.

\section{Why we are hopeful: globalization, activism, and political opportunity}

Although it would be easy to dismiss our vision for 'contextual golf' and related suggestions for change as unrealistic and unattainable, we think that there are good sociologically based reasons for optimism. For instance, and remembering from Chapters 2, 8 and 9 that social movements are most likely to be successful when the socio-political context is one that offers opportunities for change, we think that it is relevant that (in Canada especially) governments have demonstrated a willingness to make some hard decisions to regulate the cosmetic usage of chemicals. Although the golf industry is commonly exempt from these regulations, from a precautionary perspective this is still a move in the right direction. Demonstrating why the current industry-friendly system of regulation for golf is flawed (as we sought to do in Chapter 7) could ultimately compel decision makers to phase in regulations for golf courses just as they did for "lawns, vegetable and ornamental gardens, patios, driveways, cemeteries, and in parks and school yards" in Ontario (Ontario Ministry of the Environment, 2009).

It was also evident from our findings that regulatory changes around golf (e.g. mandating chemical-free courses) would potentially be embraced by many people working on golf courses. The pressure evidently faced by many superintendents to maintain pristine conditions on courses would undoubtedly be 
alleviated if regulations made it essentially impossible to achieve the pristine aesthetic. This would, we think, be one way to initiate cultural change around golf. We are also aware from our interviews that many superintendents are genuinely concerned about environmental issues. In fact, and if we remember research findings from scholars like Robbins (2007), who described how and why people used lawn chemicals despite their knowledge of the health risks associated with their usage, we might also see why regulating chemical inputs could effectively alter a system that 'produced' particular kinds of behaviours. Regulation, thought about this way, would 'produce' more ethical and less risky forms of behaviour in this case. It seems that the only group that would lose out with the sorts of regulations we are suggesting is the chemical industry - a point that would seem to be confirmed if we consider the lobbying efforts of chemical advocates when decisions about chemical bans are 'on the table' for discussion.

We are also aware that successful social movements have strong, active, and tactical leaders - what sociologists call 'social movement entrepreneurs' (Wilson et al., 2013). In Chapter 9, we featured the work and commentary of influential and respected golf course superintendent Jeff Carlson, a leading advocate of organic golf. Although Carlson is not anti-chemical per se - contending as he has that measured inputs of inorganic chemicals at key moments may reduce the need for other environmentally damaging activities - he could certainly be viewed as a social movement entrepreneur in the sense that he is demonstrating what is possible when it comes to the upkeep of a highly playable golf course that maintains a particular aesthetic, and is advocating for a more innovative and environmentally friendly form of golf. Although our vision of 'contextual golf' is more radical than this, and would require more extensive cultural changes when it comes to pursuing the pristine aesthetic that is still the dominant 'look' in the golf world, there is no doubt that Carlson is an influential figure.

So too is Brent Blackwelder, as a respected environmentalist who weighed in on golf and environmental issues in Golf Digest, an important figure in linking golf with the broader environmental movement. A profile of the recently retired Blackwelder speaks of the public education and advocacy work that is needed by leaders of a movement towards real Utopias of golf (and sport). The profile specifically outlines Blackwelder's work in testifying in front of Congress more than a hundred times on pressing environmental issues, in founding American Rivers, an organization that helped drastically expand the National Wild and Scenic Rivers System, and in initiating reform at the World Bank that directed the Bank to pay greater attention to environmental issues. In general, in his work 
as president of Friends of the Earth, Blackwelder was "renowned for speaking truth to power" (Centre for the Advancement of the Steady State Economy, n.d.).

Inspired by environmental social movement entrepreneurs such as Blackwelder, we remain hopeful that with a better understanding of the problems plaguing status quo responses to golf-related environmental problems, and with a developing plan for 'real Utopias' of golf (e.g. contextual golf), that even greener golf is possible. We also draw hope from our knowledge of successful globally connected movements for change that have emerged in recent years, as these movements have effectively connected global issues to local experiences as a way of inspiring social- and environmental justice-inspired changes (see Castells, 2012). While one book alone cannot make the difference, our hope is that the information and arguments contained herein might indeed be one piece in a larger movement towards a more socially and environmentally just game of golf.

\section{Notes}

1 Moreover, Blackwelder's vision, if carried out, would also have implications for many who currently maintain organic golf courses - not just those who manage non-organic courses. For example, organic golf superintendents would in many cases need to find solutions to problems with carbon-emitting maintenance equipment, water overuse, and in some cases the excessive input of potentially damaging organic materials all the while attending to the needs of the flora and fauna that are sharing the land through the protection of wildlife habitat spaces. Noting the current problems with economic viability and workload for those on most organic courses, Blackwelder's vision is, therefore, not exactly friendly to the organic course superintendent/owner either, although those working organic courses would likely be in philosophical agreement with Blackwelder.

2 The idea here is also to promote courses (or even golf holes) that were designed in ways that work with and feature the indigenous features of the settings the courses were created within - and are chemical free. While the principles underlying indigenous designs' have been championed by golf architects like Bill Coor and his partner golfer/ designer Ben Crenshaw (who do what has been termed 'minimalist golf'), we suggest that to be featured on the site courses would need to be chemical free. 